\title{
Evaluation of the interaction between rivers and aquifers for water supply
}

\author{
J. D. Martínez-Nájera ${ }^{1}$, C. Cruickshank-Villanueva ${ }^{2}$ \\ \& M. Berezowsky-Verduzco ${ }^{2}$ \\ ${ }^{1}$ Comisión Federal de Electricidad, Mexico \\ ${ }^{2}$ Universidad Nacional Autónoma de México, Mexico
}

\begin{abstract}
A mathematical model to evaluate coupled supply systems of rivers and aquifer types is presented; it is applied in the qualitative and quantitative estimation of extraction effects on the rivers and related aquifers under different hydrologic situations, with the purpose of determining the supply potential of the system. The model consists of the conceptual and numerical coupling of two structures that take into account different aspects of the systems under consideration. The first is for analyzing free-surface flow, and the second to carry out the analysis of flow in each one of the aquifers of interest for evaluation purposes. The coupling process occurs in iterative terms, the numerical implementation is realized by means of MODFLOW and ISIS. The approach is applied to the Papagayo River and the aquifers located in their river beds, in Guerrero State, México. The model is consistent with the field observations and numerically demonstrates that the system is able to yield the required volume by the aquifers and directly from the river.
\end{abstract}

Keywords: river-aquifer coupled systems, equations of Saint-Venant, balance of flow in aquifers and Darcy's law.

\section{Introduction}

The flow of water in streams and aquifers follow its own field equations of balance of mass, energy and constitutive relationships, each system is related with the other by coupling terms. The purpose of the work is to present an approach to evaluate the dynamic of rivers and aquifers as supply systems under realistic conditions; the numerical implementation is carried out by using 
MODFLOW and ISIS models. The combined model makes possible to evaluate the availability of water for supply aims, when underground exploitation sites are near or on river courses. One special situation arises when critical supply conditions are encountered, i.e., when the aquifer evidences trends of acute drawdown, or when the stream flow reaches minimum values.

\section{Previous works}

The work of Niazi [1] describes a similar conceptual model and applies a simplified version of the Saint-Venant's equations, based on a kinematic wave model; because of the difference in the residence times of water in rivers and aquifers, also considers the effect of the magnitude of the time elapsed during the numerical simulation of the coupled system. His results suggest that time affects the predictions of volumes exchange between both systems; [1] uses MODFLOW and an implementation in Excel of the kinematic wave model and couples them in an iterative fashion. On the other hand, here the full SaintVenant's equations are employed; therefore the analysis of the simultaneous flow of rivers and aquifers is given in a more complete approach.

Swain and Wexler [2] have been developed a general purpose code known as MODBRANCH, their scheme is similar to that of the present paper; in addition of representing works developed independently, CFE [3] and Martínez-Nájera et al. [4], their difference resides in the model used to simulate the flow in rivers and in the fact that in [2] is estimated with a redundant approach the exchange of flow between the systems in both aquifer and river modules. The scheme proposed in [2] is based on the BRANCH model of Schaffranek et al. [5], whereas in this work the ISIS code [6] is used to solve the mass and momentum balance in rivers. The ISIS code has the advantage that it is possible to simulate hydraulic structures in streams, and allows to model subcritical and supercritical flows with longitudinal and transversal topographic variations; on the other hand, the BRANCH code requires that the flow remains in a subcritical condition always, with gentle longitudinal and transversal topographic variations to ensure a flow always subcritical. The inclusion of hydraulic structures in river models are discussed in Swain [7] but not included in the BRANCH code [5]. In the scheme proposed in [2], and in this work as well, the MODFLOW code is used to simulate numerically the flow in aquifers.

From the perspective of water resources in Cruickshank-Villanueva [8] it is analyzed the relationship of superficial and underground flow in basins highlighting situations in which water is transferred from one to other medium, such as for springs and vanishing streams. He provides different exchange models as well as three specific cases to evaluate the availability and sustainability of water using numerical simulation; mention should be made of the generalization of Bouwer [9] model. In Cruickshank-Villanueva [10] it is presented an alternative approximation to a previously proposed in Adomian [11] to estimate the flow exchange in streams and aquifers, based on the model of Bouwer [9] for saturated flow; the Cruickshank-Villanueva's approximation 
depends on measurable characteristics such as width of the channel, geometry of the aquifer, permeability and anisotropy of the medium.

\section{Conceptual model and balance equations}

The Saint-Venant's equations describe the flow in shallow channels and rivers, if mass and momentum balance in the longitudinal flow is performed (Courant and Lax [12] and [6]), then it follows that

$$
\begin{aligned}
& \frac{\partial Q}{\partial x}+\frac{\partial A}{\partial t}=q \\
& \frac{\partial Q}{\partial t}+\frac{\partial}{\partial x}\left(\beta \frac{Q^{2}}{A}\right)+g A\left(\frac{\partial H}{\partial x}-S_{f}\right)=0,
\end{aligned}
$$

where $Q$ is the stream flow rate, $A$ the hydraulic flow area, $q$ is the inflow or outflow rate per unit length, $S_{f}=Q|Q| / K^{2}$ is the frictional slope, $K^{2}=A^{2} R^{4 / 3} / n^{2}$ and $R=A / P, K$ is the channel conveyance, $R$ is the hydraulic radius, $P$ is the wetted perimeter and $n$ the Manning roughness coefficient, $H$ is the free surface elevation; $\beta$ is the momentum distribution coefficient, and $g$ the acceleration of gravity. The first relation represents the mass balance and the second the momentum balance.

The mass balance for the groundwater flow and the Darcy's law (momentum balance) is described as follows (Bear [13] and Freeze and Cherry [14]),

$$
\frac{\partial}{\partial x}\left(K_{x} \frac{\partial h}{\partial x}\right)+\frac{\partial}{\partial y}\left(K_{y} \frac{\partial h}{\partial y}\right)+\frac{\partial}{\partial z}\left(K_{z} \frac{\partial h}{\partial z}\right)-Q_{s}=S_{s} \frac{\partial h}{\partial t},
$$

where $h$ is the piezometric level; $K_{x}, K_{y}$ and $K_{z}$ are the hydraulic conductivity in the principal axes, $Q_{s}$ is the volumetric flow per unit of volume of water sources and sinks, and $S_{s}$ is the specific storage.

To analyze the joint performance of rivers and aquifers is necessary to establish the coupling relationships. Depending of the difference between levels in the aquifer and river, a water exchange will be carried out with a trend toward the equilibrium; an interchange model is described by the next relationship,

$$
Q I= \begin{cases}C(H-h) & \text { if } h>L \\ C(H-L) & \text { if } h \leq L\end{cases}
$$

where $Q I$ represents the flow between the river and the aquifer, positive if goes to the aquifer; $H$ is the free surface elevation in the river, $h$ the piezometric level in the aquifer referenced to the same datum as $H$, and $C$ and $L$ are the conductance and elevation of the river bed (McDonald and Harbaugh [15]). 
The proposed model is composed by the mass and momentum balance eqn (1) for rivers and eqn (2) for aquifers, coupled by a flow exchange eqn (3). Before the iterative coupling it is necessary to have available calibrated models of the rivers and aquifers, an algorithm for the coupling is described as follow,

i. Solve the river model eqns (1)

ii. Prescribe the calculated elevations for the river water levels in the flow exchange model eqn (3)

iii. Run aquifer model eqn (2), which includes the exchange model eqn (3)

iv. If water elevations and exchange flow rates fail to converge, go back to the first step and prescribe the calculated exchange flow rates in the river model eqns (1)

In the case of study, as shown figure 1, MODFLOW [15] and ISIS [6] were used. In the work no simplifications are imposed in the balance eqns (1) to (3); although the interchange model is simple, it is possible to substitute it by more sophisticated models as in [8] and [16] without changing the proposed conceptual approximation. There are also no restrictions imposed on the geometry, parameter distribution, and initial-boundary conditions of the hydrological systems. The approach focuses widely and naturally on the simultaneous flow in rivers and aquifers and it becomes applicable for the prediction and evaluation of water supply systems [17] and [18].

Due to the difference in residence times of water in rivers and aquifers still it is necessary to analyze the effect of the magnitude of the time elapsed in the numerical simulation of coupled systems [1] and [8]. The numerical schemes of MODFLOW and ISIS are well documented in [15] and [6]; nevertheless still are pending the aspects of the strong and weak analysis of the existence, uniqueness and convergence of the coupled model.

\section{Study case}

The Papagayo River and its associated aquifers are located at the river banks locally identified as Norte, Obra de Toma and Lomas de Chapultepec, in the State of Guerrero, México, figure 1. The evaluation of the supply system was performed by Comisión Federal de Electricidad (CFE) on request from Comisión Nacional del Agua (CNA), for the updating and construction of water exploitation works in river banks, located downstream from La Venta or General Ambrosio Figueroa dam that operates the namesake hydroelectric power plant owned by CFE. The location of the exploitation works are shown in figure 2 . The wells pump the water from the river using the river banks as natural filters. At the Norte and Lomas de Chapultepec river banks there are not at present exploitation works for supply purposes. The conceptual approximation, here proposed, is applied to determine the limits of river direct contribution and through the aquifers in river banks, taking into account the current extraction rates as well as the hydrometric aspects of the river and the hydrogeological characteristics of the associated river banks. 


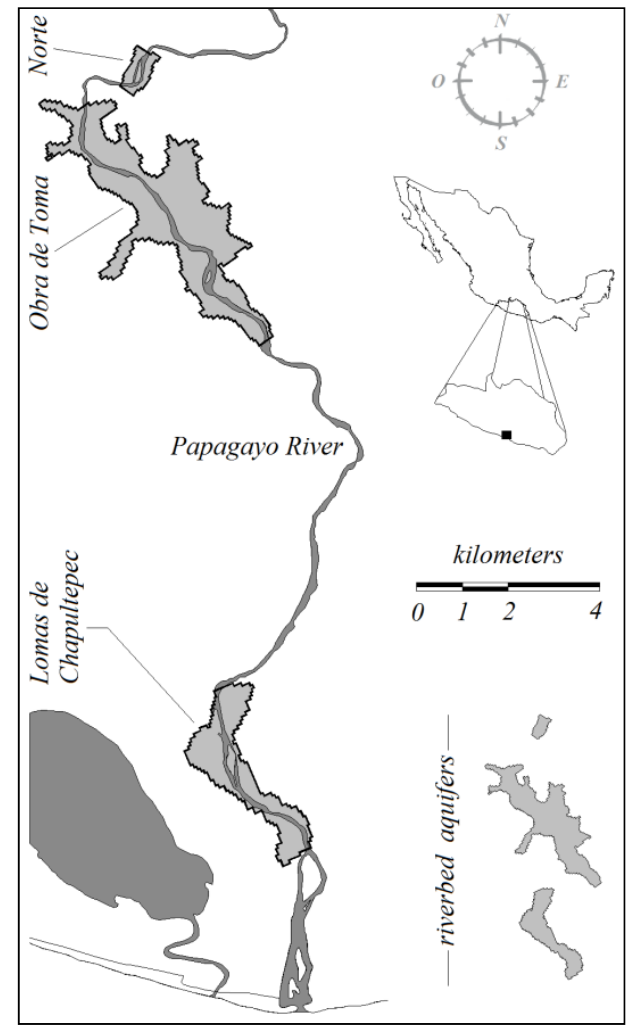

Figure 1: $\quad$ Site location. Papagayo River and Norte, Obra de Toma and Lomas de Chapultepec river banks.

\section{Stationary and transient cases}

Boundary conditions handled by ISIS for stationary case correspond to a constant flow input rate through the upstream boundary located at the north of Norte river bank, figure 1, that is combined with a condition of constant water elevation at the downstream boundary located south of the Lomas de Chapultepec river bank; the configuration of startup and calibration is assumed to be equal to the distribution of water levels observed during the period of river flow measurement. On the other hand the boundary condition for groundwater models is assumed of zero flow as well as a small vertical recharging rate due to precipitation, with an initial configuration equal to the variation of water levels obtained by ISIS-calibrated model in the first iteration of the process. With the stationary approach is possible to determine the potential supply of the river through its river banks, after assuming a constant inlet rate of flow through its upstream boundary. Constant inlet flow rates simulated in the project are 20 and $4 \mathrm{~m}^{3} / \mathrm{s}$, corresponding to the range of extreme discharges recorded at La Parota hydrometric station during the period from 1962 to 1998. 


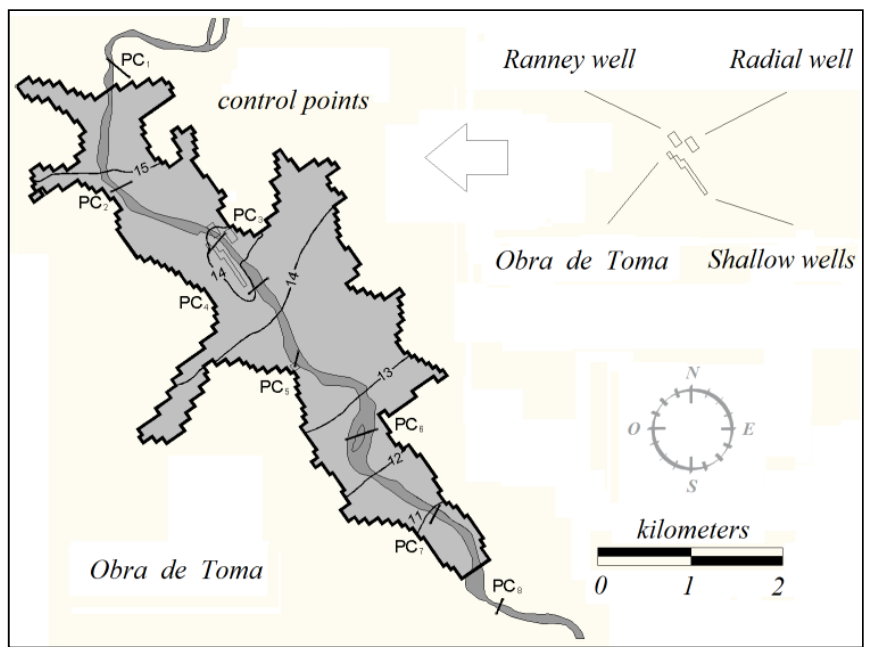

Figure 2: Impoundment works at Obra de Toma river bank. Location of topobathymetric cross sections and of control points $\mathrm{PC}_{1}-\mathrm{PC}_{8}$. Piezometric configuration calibrated at the beginning of the pulse through the northern boundary.

In the transient regime variable hydrographs at the upstream boundary of the river are specified, the series of flow rate values thus determined serves as input in ISIS to simulate the next step in the coupling iterative process. Similarly to the stationary case it is assumed a zero Neumann boundary condition with an initial configuration equal to the variation of water elevations obtained from ISIS calibrated model during the first iteration process.

\section{Obtained results}

The first scenario contemplates a constant inlet hydrograph of $20 \mathrm{~m}^{3} / \mathrm{s}$ in the northern boundary of the river. While flowing through the river bank, groundwater is extracted by radial and shallow wells with a combined yield of $1.52 \mathrm{~m}^{3} / \mathrm{s}$. Also water is extracted directly from the river at Obra de Toma facility which is explicitly considered in the ISIS surface model. As a result of extractions the river discharge decreases after exiting the river bank, this characteristic is estimated and numerically simulated to determine the sustainability of the system. According with the numerical simulation process with MODFLOW and ISIS models table 3 show the asymptotic water elevations of the river at control points $\mathrm{PC}_{1}-\mathrm{PC}_{8}$ located at Obra de Toma river bank as well as the volume contributed by the river considering a discharge of $20 \mathrm{~m}^{3} / \mathrm{s}$ in the northern boundary. 
Table 1: Results of the coupling of MODFLOW and ISIS. Water elevation and flow rates contributed by the river at control points $\mathrm{PC}_{1}-\mathrm{PC}_{8}$, considering a discharge of $20 \mathrm{~m}^{3} / \mathrm{s}$ and $4 \mathrm{~m}^{3} / \mathrm{s}$ in the northern boundary.

\begin{tabular}{|c|c|c|c|c|c|c|c|c|c|c|}
\hline \multicolumn{1}{|c|}{ Discharge of $20 \mathrm{~m}^{3} / \mathrm{s}$ at the northern boundary } \\
\hline $\mathrm{I}$ & $\mathrm{PC}_{1}$ & $\mathrm{PC}_{2}$ & $\mathrm{PC}_{3}$ & $\mathrm{PC}_{4}$ & $\mathrm{PC}_{5}$ & $\mathrm{PC}_{6}$ & $\mathrm{PC}_{7}$ & $\mathrm{PC}_{8}$ & $\begin{array}{c}\text { Flow rate contributed } \\
\text { by river }\end{array}$ \\
\hline $\mathrm{I}_{2}$ & 15.71 & 14.61 & 13.96 & 13.93 & 13.66 & 12.38 & 10.74 & 9.45 & 1.51 \\
\hline \multicolumn{7}{|c|}{ Discharge of $4 \mathrm{~m}^{3} / \mathrm{s}$ at the northern boundary } \\
\hline $\mathrm{I}$ & $\mathrm{PC}_{1}$ & $\mathrm{PC}_{2}$ & $\mathrm{PC}_{3}$ & $\mathrm{PC}_{4}$ & $\mathrm{PC}_{5}$ & $\mathrm{PC}_{6}$ & $\mathrm{PC}_{7}$ & $\mathrm{PC}_{8}$ & $\begin{array}{c}\text { Flow rate contributed } \\
\text { by river }\end{array}$ \\
\hline $\mathrm{I}_{5}$ & 15.09 & 13.70 & 13.18 & 13.16 & 12.87 & 11.89 & 10.37 & 9.07 & 1.51 \\
\hline
\end{tabular}

$\mathrm{I}_{\mathrm{i}}: i$-th iteration. $\mathrm{PC}_{\mathrm{k}}: k$-th control point.

In the second scenario it is considered a constant incoming hydrograph of 4 $\mathrm{m}^{3} /$ sat the northern boundary, table 3 presents the water asymptotic elevations in the river control points $\mathrm{PC}_{1}-\mathrm{PC}_{8}$ together with the volumes contributed during the process, the river contributes with the required sustainable flow rate.

\section{Conclusions}

A numerical approximation is presented to simulate the hydrologic behavior of river and aquifer as coupled systems under natural conditions. The associated model makes it possible to analyze their response under different supply scenarios; the numerical implementation is carried out by MODFLOW and ISIS codes. The approximation is applied to the system constituted by the Papagayo River and the aquifers located at the Norte, Obra de Toma and Lomas de Chapultepec river banks, in the State of Guerrero, México. In the analyzed cases the approximation numerically proves that river is capable of contributing with a flow rate of $1.52 \mathrm{~m}^{3} / \mathrm{s}$ by shallow, Radial and Ranney wells; as well as of 1.50 $\mathrm{m}^{3} / \mathrm{s}$ from the direct pumping facility located at Obra de Toma river bank. This situation has been registered at the site; therefore the model seems to be consistent with field observations. Under the present conditions, it has been determined that river sustains the required demanded flow rate of $3.02 \mathrm{~m}^{3} / \mathrm{s}$ and that the hydrological connection between river and aquifers is strong. The conceptual and numerical model predicts the natural response of the system when is subjected to additional extraction scenarios. The approach naturally analyses the simultaneous flow in rivers and aquifers, nevertheless it is necessary the study of the strong and weak analysis of existence, uniqueness and convergence of the coupled model. 


\section{Acknowledgements}

The authors are indebted to authorities of Comisión Federal de Electricidad and Comisión Nacional del Agua of México for providing the study area and research opportunity in the site. Also acknowledges to Ing. Gustatavo Arvizu Lara and Ing. Carlos Sánchez Linares for their support in the accomplishment of the project.

\section{References}

[1] Niazi, S. Sensitivity analysis of time-step in modeling river and aquifer interaction. Master of Science in Engineering Thesis, University of Texas at Austin, Austin, 190 pp., 2000.

[2] Swain, E.D. \& Wexler, E.J. A coupled surface-water and ground-water flow model (MODBRANCH) for simulation of stream-aquifer interaction. US Geological Survey, Techniques of Water-Resources Investigations, Book 6, Chapter A6, Washington, 125 pp., 1996.

[3] CFE 3. Subdirección Técnica/GEIC/SEH/ASV de MM. Reporte de avance de la modelación matemática del proyecto integral de abastecimiento de agua subterránea a la ciudad de Acapulco, Gro. Internal Report CFE, 86 pp., 1999.

[4] Martínez-Nájera, J.D., Flores-Ibarra, C. \& Olvera-Coronel, M. Quantitative evaluation of river-aquifer supply systems. 2001 Annual Conference of the International Association for Mathematical Geology, Cancún, México, 11 pp., 2001.

[5] Schaffranek, R.W., Baltzer, R.A. \& Goldberg, D.E. A model for simulation of flow in singular and interconnected channels. US Geological Survey, Techniques of Water-Resources Investigations, Book 7, Chapter C3, Washington, 110 pp., 1981.

[6] Halcrow / HR Wallingford. ISIS flow. User manual. Oxfordshire, UK, 318 pp., 1995.

[7] Swain, E.D. Incorporating hydraulic structures in an open-channel model. Proceedings, 1992 National Hydraulic Engineering Conference, American Society of Civil Engineers, New York, N.Y., pp. 1118-1123, 1992.

[8] Cruickshank-Villanueva, C. Relación entre las aguas superficiales y las subterráneas en una cuenca. Ingeniería Hidráulica en México, JanuaryApril, pp. 56-63, 1992.

[9] Bouwer, H. Theory of seepage from open channels. Advances in Hydroscience, No. 7, Edit. Ven-Te-Chow, McGraw Hill, NY, pp. 121172, 1976.

[10] Cruickshank-Villanueva, C. Personal communication, May 2004. On the infiltration formulas for rivers in the numerical simulation of aquifers.

[11] Adomian, G. A review of the decomposition method and some recent results for nonlinear equations. Comp. Math. Applic., Vol. 21, No. 2, pp. 101-127, 1991. 
[12] Courant, R. \& Lax, P. On nonlinear partial differential equations with two independent variables. Comm. Pure Appl. Math. Vol. 2, no. 3, pp. 255-273, 1949.

[13] Bear, J. Dynamics of fluids in porous media. American Elsevier, New York, 764 pp., 1972.

[14] Freeze, R.A. \& Cherry, J.A. Groundwater. Hemel Hempstead: PrenticeHall, Inc., Englewood Cliffs, N.J., 604 pp., 1979.

[15] [McDonald \& M.G., Harbaugh, A.W. A modular three-dimensional finite-difference ground-water flow model. U.S. Geological Survey, Open-File Report, Washington, 568 pp., 1988.

[16] Bear, J., Zaslavsky, D. \& Irmay, S. Physical principles of water percolation and seepage. UNESCO, Paris, 465 pp., 1968.

[17] Martínez-Nájera, J.D. \& Berezowsky-Verduzco, M. Evaluación del abastecimiento de sistemas río-acuífero. Ingeniería Hidráulica en México, Vol. XXIII, núm. 4, octubre-diciembre, pp. 173-187, 2008.

[18] Martínez-Nájera, J.D., Talamantes-Contreras, P., Sánchez-Linares, C. \& Olvera-Coronel, M. Análisis del acoplamiento y modelación matemática de sistemas embalse y acuífero. Ingeniería Hidráulica en México, Vol. XXIV, núm. 3, julio-septiembre, pp. 91-99, 2009. 